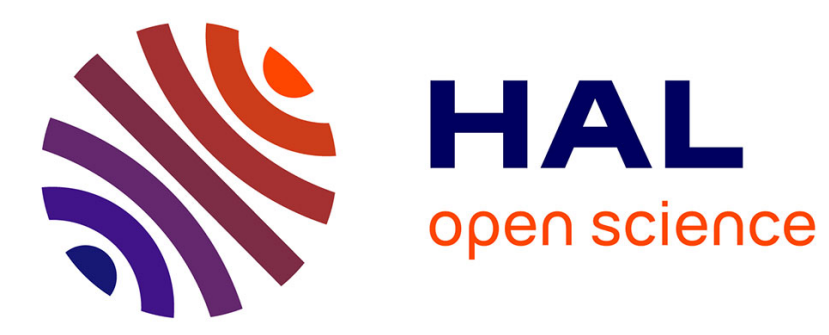

\title{
SIMULATION OF DENSITY FLUCTUATION OF POTASSIUM ADATOMS ON W (112)
}

J. Beben, J. Rogowska, K. Wojciechowski

\section{To cite this version:}

J. Beben, J. Rogowska, K. Wojciechowski. SIMULATION OF DENSITY FLUCTUATION OF POTASSIUM ADATOMS ON W (112). Journal de Physique Colloques, 1986, 47 (C7), pp.C7-145C7-148. 10.1051/jphyscol:1986726 . jpa-00225919

\section{HAL Id: jpa-00225919 https://hal.science/jpa-00225919}

Submitted on 1 Jan 1986

HAL is a multi-disciplinary open access archive for the deposit and dissemination of scientific research documents, whether they are published or not. The documents may come from teaching and research institutions in France or abroad, or from public or private research centers.
L'archive ouverte pluridisciplinaire HAL, est destinée au dépôt et à la diffusion de documents scientifiques de niveau recherche, publiés ou non, émanant des établissements d'enseignement et de recherche français ou étrangers, des laboratoires publics ou privés. 
JOURNAL DE PHYSIQUE

Colloque C7, supplément au $n^{\circ} 11$, Tome 47, Novembre 1986

C7-145

SIMULATION OF DENSITY FLUCTUATION OF POTASSIUM ADATOMS ON W (112)

\begin{abstract}
J. BEBEN, J. ROGOWSKA and K.F. WOJCIECHOWSKI
Institute of Experimental Physics, University of Wroclaw, U1. Cybulskiego 36, PL 50-205, Wroclaw, Poland
\end{abstract}

\begin{abstract}
The oscillation part of the effective indirect interaction between potassium adatoms adsorbed on (112) plane of tungsten was used to simulate the dynamics of adsorbed atoms. Simulations of field emission flicker noise have been done using a standard Monte Carlo method. A lattice used in simulation was $18 \times 29$. For three positions of the collector the mean square fluctuations have been computed. Results are in qualitative agreement with the experiment. A $c(2 \times 2)$ structure is created for the low temperature limit.
\end{abstract}

\title{
PROCEDURE
}

The considered adsorption system is potassium adsorbed on the (112) plane of tungsten. The oscillation part of the effective indirect interaction was used to simulate the synamics of adsorbed atoms. Because the distances between the adatoms are large, larger than $4.46 \Omega$, we can assume the interaction energy between the adatoms in its asymptotic form $/ 1 /$

$$
V_{a s}=A \frac{\cos \left(2 k_{F} r\right)}{r^{3}}, \quad A=\frac{9 \pi^{2}\left|w_{b}\left(2 k_{F}\right)\right|^{2}}{4 k_{F}^{5}},
$$

where:

$r$ is the distance between the adatoms, Wb is Fourier transform of a single atom pseudopotential, $k_{F}$ describes the electron density $n$ :

$$
k_{F}=\left(3 \pi^{2} n\right)^{1 / 3} \text {, In the above equations atomic units are used. }
$$

To estimate $A$ we assume according to Ashcroft $|1|$

$$
W_{b}\left(2 k_{F}\right)=\frac{-4 \cos \left(R_{m} 2 k_{F}\right)}{\Omega_{0}\left(2 k_{F}\right)^{2}},
$$

where for potassium $R_{m}=2.13$ and $\Omega_{0}=n^{-1}$. 
An attempt has been made to simulate concentration fluctuations of potassium atoms on the (112)W for a coverage equal to 0.4 . Simulations have been performed on the lattice consisting of $18 \times 29$ sites. It gives in a real scale a square of about $80 \times 80 \quad \AA^{2}$.
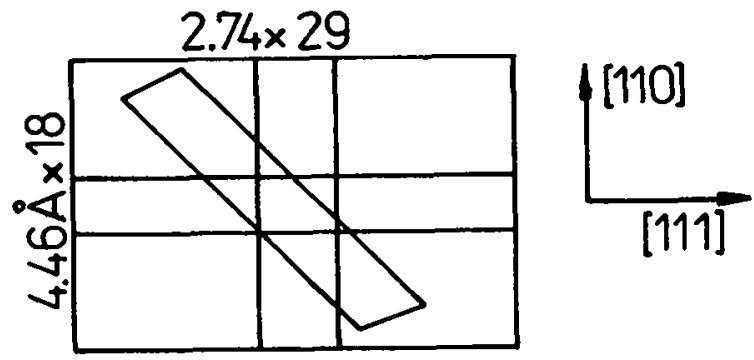

Fig. 1. The lattice used in simulation. The applied collector positions are seen.

Three collectors of the same dimensions were placed on the surface as shown in fig. 1. The standard procedure with periodic boundary conditions has been applied for simulation $|2|$. The atoms were placed randomly on the surface until a coverage equal to 0.4 has been reached. The interaction energies according to $E_{q}$ (1) have been taken into account assuming that the adatoms can occupy the adsorption sites rather than saddle positions. These energies are presented in Fig. 2 .

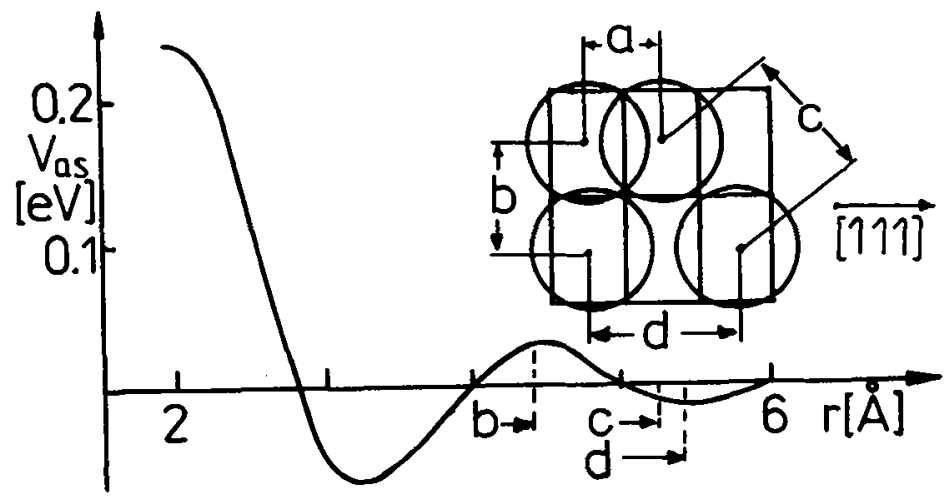

Fig. 2. Interaction energy versus adatom distance for potassium adatoms on tungsten according to $\mathrm{E}_{\mathrm{q}} / 1 /$.

When the coverage 0.4 has been reached the diffusion run started. For a randomly chosen atom the jump direction was chosen randomly. If the chosen place for the jump was occupied the atom remained at its

initial position. If empty, the interaction energy with neighbours was calculated for both initial and intended positions. If the jump did not lead to a higher energetic position the jump occurred with probability $P=1$. In the other case the jump was realized with probability 
$P=\exp (-Q / k T)$ where $T$ is the temperature of the system and $Q$ is the difference between the adatom energy $V_{a s}$ in intended $r_{i}$ and initial $r_{j}$ positions,

$$
Q=V_{a s}\left(r_{i}\right)-V_{a s}\left(r_{j}\right) .
$$

The existence of "channels" on the (112)W was merked assuming the ratio 3 to 7 of intended jumps in the (110) direction to the (111) direction. The diffusion run was performed until the whole energy of the system was minimal. It means the energy began to fluctuate about its mean value. It was after 300 Monte Carlo steps /MCS/ from a radom position of atoms. After that time the measurements began. After each MCS the number of atoms in the collector area was counted. The measurements consisted of about 300 MCS. After that time the mean square number of atoms for each collector was counted.

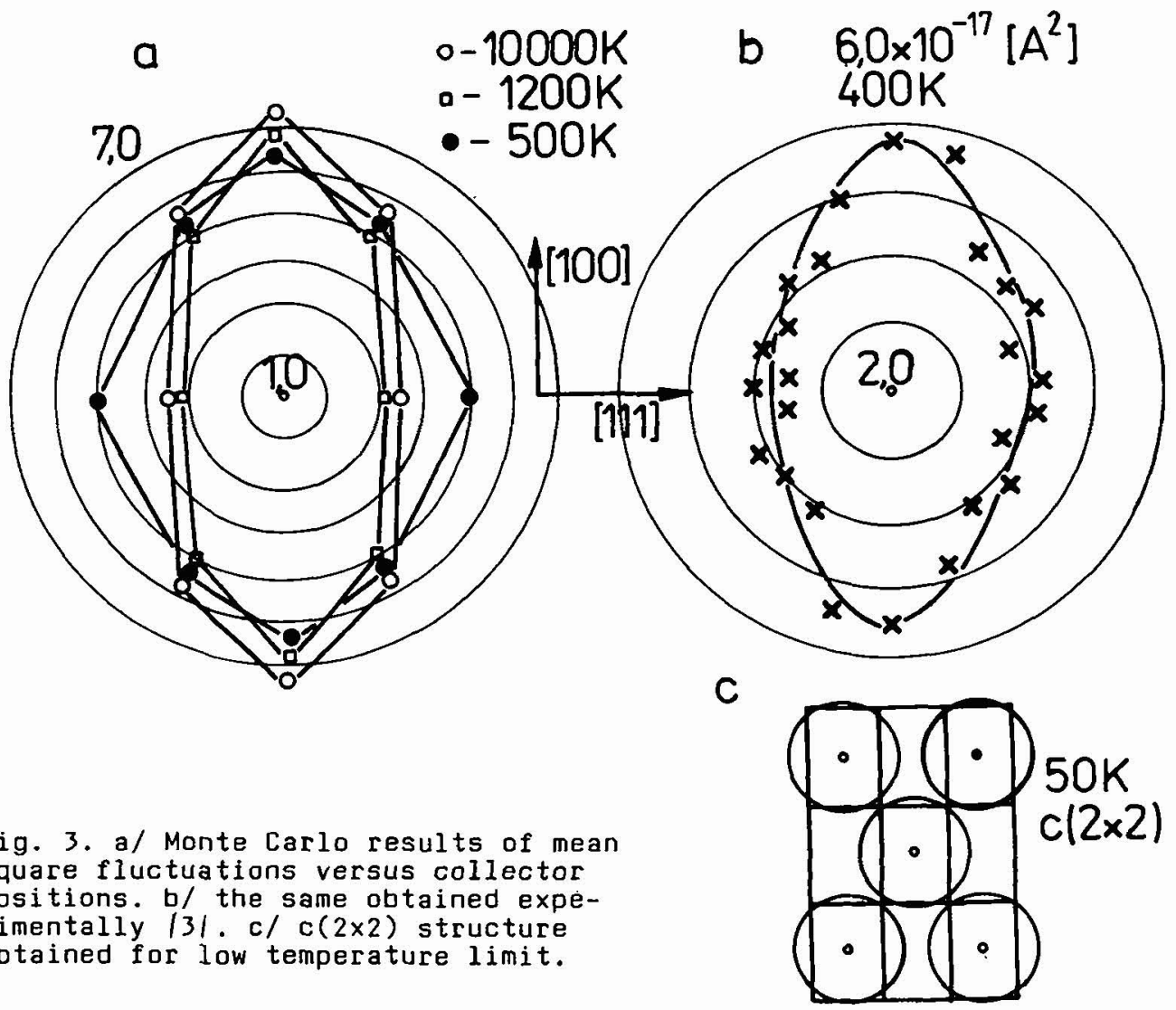

In Figure $3 a, b$, the simulations results and the comparison of them with experimental data $|3|$ are presented. Figure 3 a shows the mean square density fluctuations versus collector position obtained by simulations. Experimental results of mean square fluctuations for $T=400 \mathrm{~K}$ are presented in Fig. 3b. For $T=50 \mathrm{~K}$ the fluctuations were not observed, a $\mathrm{c}(2 \times 2)$ structure has been created $/ \mathrm{Fig} .3 \mathrm{c} /$. 


\section{DISCUSSION}

For the high temperature limit /Fig. 3a/ the angular dependence of density fluctuations obtained by simulations has a maximum for the (110) direction. It is the case where the interaction energies do not influence the jump decision and the existence of maximum is due to the symmetry of the (112) plane. With decreasing temperature the interaction energies influence the probability of jumping.

Taking $k_{k}=1.4 \AA-1$, according to $|4|$, we assume that the interaction goes thrbugh the electrons of the substrate. The experimental results of Tsong $|5|$, Casanova and Tsong $|6|$, Fink and Ehrlich $|7|$ seem to confirm such assumption. The authors have found the oscillation interaction between the adsorbed atoms for very low coverages.

The formation of clusters at about $500 \mathrm{~K}$ indicates that the interaction energies have reasonable values. Approximately good agreement of the maxima and minima of the $V_{a s}$ versus $r$ dependence with the adsorption sites is also a result of chosing $k_{F}$ for tungsten. The decrease of $T$ leads to cluster formation of $c(2 \times 2)$ structure and simultaneously the increase of the mean density fluctuation in the [111] direction is observed. The $c(2 \times 2)$ structure at the low temperature limit was observed as it was expected. For the interaction energy given by Eq.(1) it is energetically favourable.

\section{ACKNOWLEDGMENTS}

This work has been supported by the Polish Ministry for 5cience and Schools of Academic Rank within the Central Research Project on Surface $01.08 . A 1.2$.

\section{REFERENCES}

1 I.M. Torrens, Interatomic Potentials, Academic Press, New York 1972 .

2 K.Binder, Monte Carlo Method in Statistical Physics, Springer-Verlag, Berlin, 1979 .

3 J.Bęben. Ch.Kleint, 9 th Intern. Seminar on Surface Physics, Piechowice, Poland 1985 .

4 K.F. Wojciechowski, Surface Sci. 36(1973) 689.

5 T.T. Tsong, Phys.Rev.Lett. 31 (1973) 1207.

6 R.Casanova, T.T. Tsong, Thin Solid Films, 93 (1982) 41.

7 H.W. Fink, G.Ehrlich, J.Chem.Phys. 81 (1984) 4657. 